\title{
Identificatie van excellente studenten
}

\author{
Arie Kool \& Marca Wolfensberger
}

\section{Inleiding}

De aandacht voor excellentie in het hoger onderwijs is de laatste jaren, mede onder invloed van het Siriusproject, sterk gestegen (Drayer, De Jong, \& Wolfensberger, 2011). Het belang van aandacht voor excellentie is sterk verbonden met de vraag naar innovatiekracht uit de beroepspraktijk. De excellente professional speelt hierbij een sleutelrol (Veerman, 2010).

Ook binnen de verpleegkunde spelen dergelijke ontwikkelingen een rol. Recent Amerikaans onderzoek laat zien dat de kwaliteit van de verpleegkundige zorg rechtstreeks verband houdt met verbeterde patiëntuitkomsten bij complicaties en met de sterftecijfers in ziekenhuizen (Spears, Thornton, \& Long, 2008) en dat het verpleegkundeonderwijs een belangrijke rol speelt bij het tot stand brengen van excellente zorg (Sawatzki, Enns, Ashcroft, Davis, \& Harder, 2009)

De ontwikkeling tot excellente professional begint al tijdens de opleiding, onder andere door het aanbieden van programma's die ontwikkeld zijn voor de excellente student, de zogenoemde honoursprogramma's. Een excellente student maakt bij de start van haar of zijn studie onderdeel uit van een nog niet naar talent of kwaliteit gedifferentieerde studentenpopulatie. Opleidingen staan dus voor de uitdaging om studenten die de aanleg hebben om uit te groeien tot excellente professionals in hun latere beroepspraktijk, tijdig te herkennen en te laten excelleren. De belangrijkste gangbare maatstaven voor identificatie van talent zijn de resultaten van gestandaardiseerde testscores en eerdere schoolprestaties (Clark, 2002) en daarmee van intelligentie. Echter, het aanwezig zijn van deze capaciteit betekent niet per definitie dat dit talent ook daadwerkelijk ontplooid wordt. Daarnaast wordt met de honoursprogramma's gezocht naar kwaliteiten die de reguliere opleidingseisen overstijgen, bijvoorbeeld ondernemend of creatief zijn. Een helder antwoord op de vraag hoe dit ontwikkelingspotentieel in een vroeg stadium herkend kan worden, is niet voorhanden, maar kan belangrijk zijn om die mensen te rekruteren die zowel over meer dan gemiddelde capaciteiten beschikken (intelligentie) als ook over ontwikkelingspotentieel.

De insteek van onderhavige studie is om allereerst na te gaan of dergelijk ontwikkelingspotentieel inderdaad een rol speelt bij het tot bloei komen van talent. Om dit te onderzoeken wordt gekeken hoe studenten Verpleegkunde aan het eind van de studie scoren op een meting van excellente kwaliteiten en, belangrijker, of deze

* MSc, A. Kool, (a.kool@pl.hanze.nl) is werkzaam bij de Academie voor Verpleegkunde en het Lectoraat Excellentie in Hoger Onderwijs en Samenleving, Hanzehogeschool Groningen. Dr. M.V.C. Wolfensberger, is werkzaam bij het Lectoraat Excellentie in Hoger Onderwijs en Samenleving, Hanzehogeschool Groningen en bij de Universiteit Utrecht. 
score samenhangt met drie indicatoren van ontwikkelingspotentieel, te weten persoonlijkheidskenmerken, motivatie en mindset met betrekking tot persoonlijke ontwikkeling.

\section{Waarom kijken naar ontwikkelingspotentieel?}

Alhoewel schoolprestaties en intelligentie veel gebruikte voorspellers zijn voor studiesucces, zijn ze minder betrouwbaar als het gaat om de ontwikkeling van talent en als graadmeter voor toekomstig succes (Scager et al., 2012). De reden hiervoor is dat intelligentie vooral bepaalt wat iemand maximaal aankan qua niveau, terwijl andere factoren zoals motivatie of persoonlijkheid invloed hebben op wat voor prestaties en gedrag iemand daadwerkelijk zal laten zien in een onderwijssituatie. Scager et al. (2012) onderzochten of honoursstudenten meer potentieel hebben voor excellentie in hun (latere) professionele leven. De resultaten laten zien dat honoursstudenten niet alleen significant verschillen van niethonoursstudenten op het vlak van de kenmerken intelligentie, het verlangen om te leren en doorzettingsvermogen, maar ook met betrekking tot creatief denken, openstaan voor ervaringen en de gedrevenheid om te excelleren. De sterkste onderscheidende kenmerken bij Scager et al. waren het verlangen om te leren, de gedrevenheid om te excelleren en creatief te denken, terwijl er weinig verschil werd gevonden voor wat betreft intelligentie en doorzettingsvermogen. Een belangrijke aanwijzing dat het potentieel ook tot ontwikkeling gekomen is leveren Bok en Kool (2013). Zij stelden vast dat honoursalumni van de Universiteit Utrecht het potentieel ook laten zien in hun werk. Ze staan meer bevlogen in hun werk en hebben ook vaker een baan gevonden die meer in overeenstemming is met de ambities die ze tijdens hun studie hadden dan de niet-honoursalumni.

Ontwikkelingspotentieel speelt dus een rol bij de vraag of talentvolle studenten ook daadwerkelijk zullen excelleren. Bij de honoursprogramma's van de Hanzehogeschool in Groningen wordt gesteld dat ze gericht moeten zijn op het vergroten van het vermogen van studenten om kennis en ervaring productief aan te wenden in de latere beroepspraktijk, ook wel creative/productive giftedness genoemd (Renzulli, 2005). De programma's zijn dus ontwikkelingsgericht, uitgaande van een bepaalde aanleg. Het is daarom belangrijk om te weten welke kenmerken ertoe bijdragen dat aanwezig talent ook daadwerkelijk tot ontwikkeling komt.

\section{Indicatoren voor ontwikkelingspotentieel}

In dit onderzoek wordt gekeken naar drie factoren die mogelijk van invloed zijn op de mate waarin talent tot ontwikkeling komt, namelijk motivatie, mindset met betrekking tot ontwikkeling en persoonlijkheidseigenschappen. 


\section{Motivatie}

Op de eerste plaats wordt gekeken naar de motivatie van de student. Onderzoek laat zien dat honoursstudenten beschikken over een hogere intrinsieke motivatie (Kazemier, Eggens, Offringa, \& Wolfensberger, 2014; Wolfensberger en Offringa, 2012). Motivatie speelt daarnaast een rol bij de kans dat een bepaald talent ook tot ontwikkeling komt. Excellentie is immers vaak niet alleen het resultaat van talent, maar bijvoorbeeld ook van hard werk. Schouwenburg en Stevens (2002) maken hiervoor naast het onderscheid tussen intrinsieke en extrinsieke motivatie ook de distinctie tussen remmende krachten (bijvoorbeeld faalangst en uitstelgedrag) en versterkende krachten (toekomstperspectief), die van invloed kunnen zijn op studiemotivatie. Inzicht in de grondslagen van studiemotivatie zou daarmee een bruikbare indicator kunnen zijn voor ontwikkelingspotentieel.

\section{Mindset met betrekking tot ontwikkeling}

Een belangrijke indicator voor het vermogen om bepaalde kwaliteiten te ontwikkelen is, naast het hebben van voldoende aanleg, de mate waarin een student zichzelf ontwikkelbaar vindt. In Dweck, Mangele en Good (2004) wordt beschreven dat er een relatie is tussen de opvattingen die studenten hebben over hun eigen intelligentie en hun doeloriëntatie. Hierbij wordt een onderscheid gemaakt tussen een incremental theory ten aanzien van intelligentie en een entity theory. Studenten met een entity theory-opvatting zien intelligentie als onveranderbaar; lerenden met een incremental theory geloven dat hun intelligentie kneedbaar is en kan worden vergroot door inspanning. Leerlingen en studenten kunnen worden onderscheiden op basis van hun overtuiging over de mogelijkheid te kunnen groeien (een zogenoemde growth mindset) of het beste moeten proberen te maken van het beschikbare vermogen (fixed mindset).

\section{Persoonlijkheidskenmerken}

Ten slotte wordt de rol van persoonlijkheid besproken. Iemands persoonlijkheid verwijst naar de onderscheidende gedachten, emoties en gedragingen die de manier karakteriseren waarop een individu zich aanpast aan de wereld (Santrock, 2009). Hierdoor kan iemands persoonlijkheid mede bepalend zijn voor de ontwikkeling van talent. Onderzoek laat bijvoorbeeld zien dat bepaalde aspecten van persoonlijkheid betere voorspellers zijn van studieprestaties dan intelligentie. Volgens Kappe (2012) verklaart consciëntieus zijn (ordelijkheid) bijvoorbeeld vijf keer zoveel variantie van studieprestaties als intelligentie.

Hoewel er nog niet veel onderzoek is gedaan waarin gekeken wordt of en hoe persoonlijkheid gebruikt kan worden als voorspeller voor de ontplooiing van talent, bestaat er wel onderzoek waarin gekeken wordt hoe de persoonlijkheid van reguliere studenten verschilt van studenten uit honoursprogramma's. Zo laat Clark (2002) bijvoorbeeld zien dat honoursstudenten te onderscheiden zijn op onderdelen van de 'Myers-Briggs Type Indicator' (MBTI), met name op de schaal 'iNtuitive-Sensing', waarbij honoursstudenten hoger scoren op het intuitieve uiteinde van de schaal in vergelijking met de populatie als geheel. Dat betekent dat 
zij een voorkeur hebben voor de betekenis en patronen van informatie. Ze leren meer door nadenken dan door directe ervaring.

In het huidige onderzoek werd gekeken naar persoonskenmerken die gebaseerd zijn op de 'Multiculturele Persoonlijkheidsvragenlijst' (MPV) (Van der Zee \& Oudenhoven-van der Zee, 1999). De MPV is een variant van het Big Five-Factormodel voor persoonlijkheid. Deze MPV sluit beter aan bij het specifieke doel van dit onderzoek dan de klassieke Big Five. De MPV is ontwikkeld om na te gaan of mensen die uitgezonden worden naar het buitenland daar voldoende voor toegerust zijn en is dus bedoeld om voorspellingen te kunnen doen over hoe mensen zullen reageren op onbekende, onverwachte, nieuwe situaties. Dit past bij de gedachte dat honoursstudenten gericht zullen moeten zijn op nieuwe, onbekende uitdagingen, waar nog geen kant-en-klare oplossingen voor beschikbaar zijn.

De multiculturele persoonlijkheidsvragenlijst kent vijf componenten:

- Culturele Empathie: het vermogen om empathie te hebben ten aanzien van de gedachten, gevoelens en gedragingen van diverse individuen;

- Open Houding: het vermogen een onbevooroordeelde en open houding te hebben ten opzichte van verschillende groepen en cultureel verschillende waardesystemen;

- Emotionele Instabiliteit: het vermogen om kalm te blijven in stressvolle en nieuwe situaties (wordt gemeten met vragen naar gebrek aan stabiliteit);

- Sociaal Initiatief: het vermogen initiatief te nemen en nieuwe situaties op een actieve manier te benaderen.

- Inflexibiliteit: de neiging om onbekende situaties te zien als een uitdaging en het eigen gedrag aan te passen aan nieuwe en dubbelzinnige situaties (wordt gemeten met vragen naar gebrek aan flexibiliteit).

\section{Het huidige onderzoek}

Samengevat wordt dus nagegaan of motivatie, mindset met betrekking tot ontwikkeling en persoonlijkheidskenmerken voorspellers zijn van de kans dat aanwezig talent ontwikkeld zal worden. Om dit na te gaan is een correlationeel retrospectief onderzoek gedaan bij de Academie voor Verpleegkunde. Bij studenten in het laatste jaar van de bacheloropleiding Verpleegkunde is nagegaan welke indicatoren voor ontwikkelingspotentieel samenhangen met de beoordeling van studenten door docenten op de indicatoren voor excellente studentprestaties (zie figuur 1).

De gedachte hierachter is dat een samenhang een aanwijzing is dat deze indicatoren gebruikt kunnen worden bij de identificatie van kandidaat-studenten voor honoursprogramma's. 


\begin{tabular}{|c|c|}
\hline $\begin{array}{l}\text { Indicatoren voor } \\
\text { ontwikkelingspotentieel } \\
\text { - Motivatie } \\
\text { - Mindset } \\
\text { - Persoonlijkheid }\end{array}$ & $\begin{array}{l}\text { Indicatoren voor excellente } \\
\text { studentprestaties } \\
\text { - Analytisch vermogen } \\
\text { - Kritische reflectie } \\
\text { - Vakinhoudelijk leiderschap } \\
\text { - Innovatief handelen } \\
\text { - Passie/gedrevenheid } \\
\text { - Empathie en zelfstandigheid }\end{array}$ \\
\hline
\end{tabular}

\section{Figur 1 Conceptueel model}

\section{Methode}

De populatie betrof studenten van de Academie voor Verpleegkunde van de Hanzehogeschool Groningen. Voor dit onderzoek zijn alle vierdejaarsstudenten (deeltijd, voltijd en duaal) van de Academie tijdens hun praktijkleerperiode benaderd $(N=142)$. Deze studenten vulden een digitale vragenlijst in. 92 ingevulde lijsten zijn teruggekomen, wat 88 bruikbare vragenlijsten heeft opgeleverd (een respons van 54,3\%). Voor de docentenbeoordeling werden alle betrokken docenten gevraagd de studenten die zij begeleid hadden aanvullend te beoordelen op een hiervoor ontwikkelde lijst van indicatoren voor excellente studentprestaties. Hier was de respons $100 \%$.

\section{Vragenlijsten voor de indicatoren voor ontwikkeling van potentieel}

De drie theoretische constructen die in de vragenlijst werden opgenomen zijn motivatie, mindset en persoonlijkheid. Deze drie variabelen zijn geoperationaliseerd door gebruik te maken van bestaande vragenlijsten, te weten de 'Checklist StudieMotivatie' (CSM), de vragenlijst 'Mindset' en de 'Multiculturele Persoonlijkheidsvragenlijst' (MPV).

\section{Motivatie}

Om motivatie te meten is gebruik gemaakt van de Checklist Studie Motivatie (CSM; Schouwenburg \& Stevens, 2002), die bestaat uit zeven subschalen: procrastinatie (uitstelgedrag); studie te moeilijk; toekomstperspectief; extrinsieke belemmeringen en verwachtingen; academische integratie; en prestatiemotivatie. De CSM kent betrouwbaarheidswaarden variërend van .60 tot .79. De gevonden betrouwbaarheidswaarden in dit onderzoek zijn weergegeven in tabel 1.

\section{Mindset}

Om de mindset met betrekking tot ontwikkeling te meten, werd gebruik gemaakt van een door Dweck ontwikkelde set van zes vragen (http://www.mindsetonline .com). Een voorbeelditem is: "Je intelligentie is iets waar je niet veel aan kan ver- 


\section{Tabel 1 Betrouwbaarheid van de schalen van de 'Checklist StudieMotivatie'}

\begin{tabular}{lc}
\hline Schalen & $\alpha$ Voorbeeldvraag \\
\hline Procrastinatie & $.72 \mathrm{lk}$ stel vaak zaken te lang uit. \\
Studie te moeilijk & .56 Studeren kost me (te) veel energie. \\
Toekomstperspectief & $.50 \mathrm{lk}$ ben gaan studeren om later veel geld te kun- \\
& nen verdienen. \\
Extrinsieke belemmeringen & $.57 \mathrm{lk} \mathrm{heb} \mathrm{echt} \mathrm{niet} \mathrm{genoeg} \mathrm{tijd} \mathrm{voor} \mathrm{mijn} \mathrm{studie.}$ \\
Extrinsieke verwachtingen & $.16 \mathrm{lk}$ studeer omdat in ons gezin iedereen heeft \\
& gestudeerd of gaat studeren. \\
Academische integratie & $.28 \mathrm{lk}$ heb weinig contact met medestudenten. \\
Prestatiemotivatie & $.60 \mathrm{lk}$ werk niet graag voor een zesje, maar liever \\
& voor een hoger cijfer. \\
\hline
\end{tabular}

Tabel 2 Betrouwbaarheid van de schalen van de 'Multiculturele Persoonlijkheidsvragenlijst'

\begin{tabular}{lrr}
\hline Schalen & $\boldsymbol{\alpha}$ & Voorbeeldstellingen \\
\hline Culturele empathie & .72 & Begrijpt de gevoelens van anderen \\
Open houding & .83 & Is geïnteresseerd in andere culturen \\
Sociaal initiatief & .77 & Is geneigd het woord te nemen \\
Emotionele instabiliteit & .84 & Wisselt vaak van stemming \\
Inflexibiliteit & .73 & Werkt meestal volgens een vast stramien \\
\hline
\end{tabular}

anderen." In een studie van Dweck uit 1999 (in Blackwell, Treszniewski \& Dweck, 2007) wordt een interne consistentie gemeld van .78. De gevonden betrouwbaarheid van de schalen in dit onderzoek zijn .88 voor de schaal fixed mindset en .73 voor growth mindset.

\section{Persoonlijkheid}

Voor het meten van de variabele persoonlijkheid is gebruik gemaakt van de 'Multiculturele Persoonlijkheidsvragenlijst' (Van der Zee \& Oudenhoven-van der Zee, 1999). De multiculturele persoonlijkheidsvragenlijst kent vijf componenten: 'Culturele Empathie', 'Open Houding', 'Emotionele Instabiliteit', 'Sociaal Initiatief' en 'Inflexibiliteit'. In plaats van vragen worden in deze lijst stellingen gebruikt. De betrouwbaarheidswaarden van de schalen van de MPV variëren volgens Maesen de Sombreff en Van der Linnenbank (2003) tussen .72 en .86. De begripsvaliditeit is volgens de COTAN-beoordeling goed. De betrouwbaarheidswaarden die in het huidige onderzoek zijn gevonden, zijn weergegeven in tabel 2.

\section{Indicatoren voor excellente studentprestaties}

Om te komen tot indicatoren voor excellente studentprestaties is gebruik gemaakt van een kwalitatieve exploratieve methode. Hiervoor zijn interviews 
afgenomen met vijf ervaren docenten die betrokken zijn bij het begeleiden en beoordelen van het praktijkleren in het laatste studiejaar. De reguliere beoordeling bestaat uit een waardering uitgedrukt in een cijfer voor de mate waaraan aan de geformuleerde eindtermen/learning outcomes is voldaan. Voor dit onderzoek werden aanvullende kenmerken/kwaliteiten gezocht om excellente studentprestaties te karakteriseren. De centrale vraag was: wat zijn kenmerken/kwaliteiten die je ziet bij studenten die volgens jou excellent zijn? Dit heeft geleid tot een lijst van zeven indicatoren op grond waarvan de studenten van de Academie voor Verpleegkunde als excellent beschouwd worden:

- analytisch vermogen

- kritische reflectie

- vakinhoudelijk leiderschap

- innovatief handelen

- passie/gedrevenheid

- empathie

- zelfstandigheid.

De docentbegeleiders scoorden al hun studenten op een vijfpuntsschaal ('5 = excellent scorend', ' 1 = ondergemiddeld scorend'). Om na te gaan of de zeven eigenschappen samen voldoende onderlinge samenhang laten zien om samen te kunnen gelden als maatstaf voor studentprestaties is de toets voor de interne consistentie $(\alpha=.91)$ afgenomen van de zeven eigenschappen ten opzichte van de totale score.

\section{Data-analyse}

\section{Descriptieve analyse}

Allereerst is nagegaan hoe in de huidige steekproef de procentuele verdeling van excellente, gemiddelde en benedengemiddelde studenten is. Hiertoe is het databestand opgesplitst in drie groepen; studenten die een excellente $(M<2)$, een gemiddelde $(M=2,3$ of 4$)$ en een lager dan gemiddelde $(M>4)$ score kregen van de docent. Als vuistregel wordt gesteld dat binnen een studentenpopulatie $80 \%$ van de totale populatie getypeerd kan worden als gemiddeld begaafd, $10 \%$ als lager dan gemiddeld begaafd en $10 \%$ als bovengemiddeld begaafd. De huidige verdeling komt hier dicht bij in de buurt. 
Tabel $3 \quad$ Indeling van de groepen studenten verpleegkunde

\begin{tabular}{lll}
\hline Groepen & Aantal studenten & Percentage \\
\hline Bovengemiddeld/excellent & 6 & 6,8 \\
Gemiddeld & 69 & 78,4 \\
Lager dan gemiddeld & 13 & 14,8 \\
Totaal & 88 & 100 \\
\hline
\end{tabular}

Op basis van de docentenoordelen is de verdeling tot stand gekomen zoals weergegeven in tabel 3 .

\section{Hypotheses}

De volgende verwachtingen werden onderzocht: ten aanzien van motivatie (de CSM) is de verwachting dat de hoogst scorende studenten lagere scores behalen op procrastinatie, studie te moeilijk, externe belemmeringen, externe verwachtingen en studie valt tegen; en hogere scores op toekomstperspectief, academische integratie en prestatiemotivatie. Ten aanzien van mindset met betrekking tot ontwikkeling is de verwachting dat de hoogst scorende studenten lager scoren op het hebben van een fixed mindset en hoger op het hebben van een growth mindset. Met betrekking tot persoonlijkheidskenmerken is de verwachting dat de hoogst scorende studenten hoger scoren op culturele empathie, open mind en sociaal initiatief; en lager op emotionele instabiliteit en inflexibiliteit.

\section{Resultaten}

Om na te gaan of motivatie, mindset en persoonlijkheidskenmerken ten aanzien van ontwikkeling samenhang vertonen met excellente studentprestaties zijn correlaties berekend tussen de indicatoren voor ontwikkelingspotentieel en de somscore van de docentwaardering.

\section{Motivatie}

In tabel 4 zijn de correlaties weergegeven tussen de schalen van de CSM en de scores op de studentprestaties. Bij de CSM is er geen significante correlatie aangetoond tussen de verschillende subschalen van de CSM en het totaal van de studentprestaties.

\section{Mindset}

In tabel 5 zijn de correlaties weergegeven tussen de schalen van de mindset en de scores op de studentprestaties. Tussen mindset en studentprestaties is geen significante correlatie gevonden. 
Tabel 4 Correlaties tussen CSM en excellente studentprestaties

\begin{tabular}{llllllllll}
\hline & $\mathbf{I}$ & $\mathbf{2}$ & $\mathbf{3}$ & $\mathbf{4}$ & $\mathbf{5}$ & $\mathbf{6}$ & $\mathbf{7}$ & $\mathbf{8}$ & $\mathbf{9}$ \\
\hline Procrastinatie (I) & $\mathrm{I}$ & & & & & & & & \\
Studie te moeilijk (2) & $-.49^{* *}$ & $\mathrm{I}$ & & & & & & & \\
Toekomstperspectief (3) & -.10 & -.05 & $\mathrm{I}$ & & & & & & \\
Ext. belemmeringen (4) & $-.48^{* *}$ & $-.47^{* *}$ & .10 & $\mathrm{I}$ & & & & & \\
Ext. verwachtingen (5) & -.16 & $-.37^{* *}$ & -.05 & -.14 & $\mathrm{I}$ & & & & \\
Acad. integratie (6) & -.09 & $-.24^{*}$ & -.06 & $-.22^{*}$ & $-.30^{* *}$ & $\mathrm{I}$ & & & \\
Prestatiemotivatie (7) & .11 & .16 & $-.30^{* *}$ & $.19^{*}$ & .06 & .00 & $\mathrm{I}$ & & \\
Studie valt tegen (8) & $-.23^{*}$ & -.11 & -.08 & -.13 & -.05 & -.08 & -.10 & 1 & \\
Excellente studentprestaties & -.07 & -.10 & -.14 & .05 & .11 & .17 & .12 & -.06 & I \\
(9) & & & & & & & & & \\
\hline
\end{tabular}

$* \mathrm{p}<.05, * * \mathrm{p}<.01$

Tabel 5 Correlaties tussen de mindset en het totaal van de studentprestaties

\begin{tabular}{llll}
\hline & I & $\mathbf{2}$ & $\mathbf{3}$ \\
\hline Fixed mindset (I) & I & & \\
Growth mindset (2) & $.49^{*}$ & I & \\
Excellente studentprestaties (3) & -.11 & .11 & I \\
\hline
\end{tabular}

$* \mathrm{p}<.05, * * \mathrm{p}<.01$

\section{Persoonlijkheid}

In tabel 6 zijn de correlaties weergegeven tussen de schalen van de MPV en de scores op de studentprestaties. Het totaal van de studentprestaties correleert significant met alle schalen van de MPV. Ten aanzien van de subschalen kon worden geconcludeerd dat bij culturele empathie, open mind en sociaal initiatief sprake was van een positief verband: hoe hoger de score op deze schalen, hoe hoger de waardering door docenten. Ten aanzien van emotionele instabiliteit en inflexibiliteit werd een negatief verband vastgesteld, waarbij de score als volgt moet worden geïnterpreteerd: hoe minder stabiel en hoe minder flexibel de studentscore, hoe lager de waardering door docenten. Het sterkste verband werd vastgesteld ten aanzien van open mind, gevolgd door culturele empathie, sociaal initiatief, emotionele instabiliteit en tenslotte inflexibiliteit.

\section{Regressieanalyse}

Met behulp van een regressieanalyse werd de gecombineerde voorspellende waarde van de subschalen van de MPV onderzocht. Welke combinatie van variabelen voorspelt de afhankelijke variabele studieprestatie het best? De combinatie 'open houding', 'emotionele stabiliteit' én 'culturele empathie' heeft de meeste significantie én de grootste voorspellende waarde met een $\mathrm{R}$ van .37 en een verklaarde variantie van $15 \%$ ten aanzien van de scores op de studentprestaties. In tabel 7 is dit model weergegeven. De resultaten laten zien dat in dit model alleen 
Tabel 6 Correlaties tussen de schalen van de MPV en het totaal van de studentprestaties

\begin{tabular}{|c|c|c|c|c|c|c|}
\hline & I & 2 & 3 & 4 & 5 & 6 \\
\hline Culturele empathie (I) & I & & & & & \\
\hline Open houding (2) & $.45^{* *}$ & I & & & & \\
\hline Sociaal initiatief (3) & .02 & $.24^{*}$ & 1 & & & \\
\hline Emotionele instabiliteit (4) & $-.18^{*}$ & -.03 & $-.32^{* *}$ & I & & \\
\hline Inflexibiliteit (5) & -.08 & $-.21^{*}$ & .01 & $.25^{*}$ & I & \\
\hline $\begin{array}{l}\text { Excellente studentpresta- } \\
\text { ties (6) }\end{array}$ & $.20^{*}$ & $.33^{* *}$ & $.20^{*}$ & $-.20^{*}$ & $-.20^{*}$ & I \\
\hline
\end{tabular}

Tabel $7 \quad$ Het best voorspellende model van excellente studentprestaties

\begin{tabular}{|c|c|c|}
\hline \multirow[b]{2}{*}{ Variabele } & \multicolumn{2}{|c|}{ Excellente studentprestaties } \\
\hline & $\beta$ & $(95 \% \mathrm{Cl})$ \\
\hline Constante & 16.54 & {$[6,0 \mathrm{I}, 27.07]$} \\
\hline Open houding & $.27^{*}$ & {$[.08, .62]$} \\
\hline Culturele empathie & .09 & {$[-.71, .30]$} \\
\hline Emotionele instabiliteit & $-.20 *$ & {$[.00, .5 \mathrm{I}]$} \\
\hline
\end{tabular}

$* \mathrm{p}<.05$

'open houding' en 'emotionele instabiliteit' significante voorspellers zijn van excellente studentprestaties. Net als bij de correlatieberekeningen is een open houding een positieve voorspeller van excellente studentprestaties, terwijl emotionele instabiliteit een negatieve voorspeller is.

\section{Discussie en conclusies}

Het doel van het huidige onderzoek was om na te gaan of er indicatoren zijn die voorspellend zijn voor het tot ontwikkeling komen van talent. De resultaten laten zien dat indicatoren die te maken hebben met het aanpassen aan de (multiculturele) omgeving voorspellend zijn. Meer precies laat het huidige onderzoek zien dat culturele empathie, open mind en sociaal initiatief positief samenhangen met hogere docentscores in termen van excellentie, terwijl emotionele instabiliteit en inflexibiliteit juist negatief samenhangen. De voorspellende waarde van $15 \%$ is een interessante aanwijzing om dit spoor te vervolgen.

Tegen de verwachting in bleken motivatie en mindset met betrekking tot ontwikkeling in het huidige onderzoek niet samen te hangen met studentprestaties in termen van excellentie. Opvallend is dat de betrouwbaarheidswaarden van de CSM in dit onderzoek laag tot erg laag zijn (zie tabel 1). Een conclusie over moti- 
vatie als voorspeller voor ontwikkeling van potentieel kan op grond van deze vragenlijst niet goed worden getrokken.

Toch denken we dat motivatie en dan met name intrinsieke motivatie wel een belangrijke rol kan spelen bij het tot ontwikkeling komen van talent. Uit ander onderzoek blijkt bijvoorbeeld dat honoursstudenten hoger scoren op intrinsieke motivatie (Kazemier et al., 2014). Daarnaast hebben extrinsiek gemotiveerde honoursstudenten minder belangstelling voor docenten die talent tot ontwikkeling proberen te laten komen door middel van zelfregulerende leerstrategieën (Kazemier et al., 2014).

Wat betreft mindset tot ontwikkeling is het wellicht zo dat dit tijdens de eindfase van de studie minder relevant is. Studenten zijn immers enerzijds reeds door alle stadia van volhouden en keuzes maken gegaan en hebben laten zien dat ze zich voldoende kunnen ontwikkelen om aan de eisen van de studie te voldoen. Anderzijds zijn de begeleidende docenten weer verschillend in hun verwachtingen over de ontwikkelingsmogelijkheden van studenten en de mate waarin ze daar in hun begeleiding blijk van geven.

\section{Limitaties en suggesties voor vervolgonderzoek}

De conclusie dat de gevonden samenhang daadwerkelijk gebruikt kan worden bij het identificeren en wellicht selecteren van studenten voor honoursprogramma's kan nog niet getrokken. De reden hiervoor is dat het huidige onderzoek (a) retrospectief van aard is, en (b) niet gekeken heeft naar wat bepaalt of studenten daadwerkelijk goed functioneren in een honoursprogramma. Daartegenover staat dat gekeken is naar kwaliteiten van de excellente professional (het beoogde eindstadium van toekomstige honoursprogramma's) en dat hiermee impliciet honourskwaliteiten aan de orde zijn geweest. In vervolgonderzoek zullen de indicatoren (met name de MPV) ingezet worden bij eerstejaars. Deze zullen daarna gevolgd worden in het vervolg van hun studie om op die manier na te kunnen gaan wat nu werkelijk de voorspellende waarde zal zijn.

Een andere limitatie van dit onderzoek is dat uitkomsten van het huidige onderzoek niet zomaar gegeneraliseerd kunnen worden naar andere studierichtingen. Scager et al. (2012) stelden bijvoorbeeld reeds vast dat per opleiding verschillende combinaties van eigenschappen indicatief zijn voor excellentie. In vervolgonderzoek zullen de indicatoren ook getest moeten worden bij een bredere studentenpopulatie dan alleen verpleegkundestudenten.

\section{Implicaties voor de praktijk}

De uitkomsten geven aan dat er aanvullende indicatoren bruikbaar kunnen zijn om naast de aanwezige capaciteit ook het ontwikkelingspotentieel in beeld te brengen en deze informatie eventueel te gebruiken bij de rekrutering van studenten voor honoursprogramma's. Een effectieve en rechtvaardige wijze om te diffe- 
rentiëren is van groot belang. Aan de uitkomsten van de rekrutering zijn grote consequenties verbonden: voor studenten opdat hun mogelijkheden geoptimaliseerd kunnen worden, voor het onderwijs om bij te kunnen dragen aan de verhoging van kwaliteit en output van het onderwijs en voor de maatschappij als geheel om te kunnen voldoen aan de eisen van deze tijd. Naast scouting op talent in termen van intelligentie en schoolprestaties kan het weleens van belang zijn om ook te scouten op de mogelijkheid om het aanwezige talent daadwerkelijk te laten bloeien. Het huidige onderzoek suggereert (voorzichtig) dat hierbij een rol is weggelegd voor het differentiëren op basis van de aanwezigheid van persoonskenmerken zoals het hebben van een open houding en emotionele stabiliteit.

\section{Referenties}

Blackwell, L.S., Trzesniewski, K., \& Dweck, C.S. (2007). Implicit theories of intelligence predict achievement across an adolescent transition: A longitudinal study and an intervention. Child Development, 78, 246-263.

Bok, M., \& Kool, A. (2013). Excellentie nader onderzocht. Tijdschrift voor Hoger Onderwijs \& Management, 20, 42-46.

Clark, L. (2002). A Review of the Research on Personality Characteristics of Academically Talented College Students. In C.L. Luiks \& L. Clark (Eds.), Teaching and learning in honors (pp. 7-20). Lincoln: NCHC. Geraadpleegd op: http://digitalcommons.unl.edu/ nchcmono/9.

Drayer, L., De Jong, N., \& Wolfensberger, M. (2011). Leren excelleren. Excellentieprogramma's in het HBO: een state of the art. Utrecht: Universiteit van Utrecht, Groningen: Hanzehogeschool.

Dweck, C.S., Mangele, J.A., \& Good, C. (2004). Motivational Effects on Attention, Cognition and Performance. In D. Yun Dai \& R.J. Sternberg, (Eds.), Motivation, Emotion and Cognition, integrative perspectives on intellectual functioning and development (pp. 41-57). New Jersey: Lawrence Erlbaum Associaties.

Kappe, R. (2012). Predicting academic success in higher education: what's more important than being smart? European Journal of Psychology of Education. (27), 605-619.

Kazemier, E.M., Eggens, L., Offringa, G.J., \& Wolfensberger, M.V.C. (2014) Honours- en reguliere studenten in het hbo: een vergelijking van motivatie, leerstrategieën \& voorkeur voor doceerbenadering. Tijdschrift voor Hoger Onderwijs, 31/32(4/1), 106-123.

Maesen de Sombreff, P., \& Van der Linnenbank, P. (2003). Handleiding Multiculturele Persoonlijkheids Vragenlijst, Een multidimensioneel instrument voor multiculturele effectiviteit. Den Haag. DOI http://dx.doi.org/10.1080/00224545.2010.503718 vragenlijsten.

McCrae, R.R. (2011). Personality Theories for the 21st Century. Teaching of Psychology, 38(3), 209-214.

Renzulli, J.S. (2005). Equity, Excellence, and Economy in a System for Identifying Students. Gifted Education: A Guidebook. Connecticut: University of Connecticut, University of Virginia, Yale University.

Santrock, J.W. (2009). Educational Psychology. New York: McGraw-Hill.

Sawatzki, J.A., Enns, C.L. Ashcroft, T.J., Davis, P.L., \& Harder, B.N. (2009). Teaching excellence in nursing education: a caring framework. Journal of Professional Nursing, 25 (5), 260-266. 
Scager, K., Akkerman, S.F., Keesen F., Mainhard, M.T., Pilot, A., \& Wubbels, T. (2012). Do honors students have more potential for excellence in their professional lives? The International Journal of Higher Education and Educational Planning, 64, 19-39.

Schouwenburg, H.C., \& Stevens I.L. (2002). De Checklist StudieMotivatie CSM'96. Groningen: Rijksuniversiteit Groningen.

Siegel, L., \& Siegel, L.C. (1965). Educational set: a determinant of acquisition. Journal of Educational Psychology, 56, 1-12.

Spears, P., Thornton, D., \& Long, L. (2008). Journey to Nursing Excellence: Building Partnerships for Success. Nurse Leader, 59-66.

Van der Zee, K.I. \& Oudenhoven-van der Zee, J.P. (1999). De Multiculturele Persoonlijkheids Vragenlijst voor Multiculturele Effectiviteit. Handleiding. Groningen: RUG, vakgroep Psychologie.

Veerman, C. (2010). Differentiëren in Drievoud. Den Haag: Commissie Toekomstbestendig Hoger Onderwijs Stelsel, OCSW.

Wolfensberger, M.V.C., \& Offringa, G.J. (2012). Qualities Honors Students Look for in Faculty and Courses revisited. Journal of the National Honors Council, Fall/Winter, 171-182. 